\title{
IDENTIFIKASI SISTEM PESAWAT UDARA TANPA AWAK SAYAP TETAP
}

\author{
Abdul Majid ${ }^{1}$, Tri Kuntoro Priyambodo ${ }^{2}$
}

\begin{abstract}
Abstrak: Penelitian mengenai pesawat udara tanpa awak berkembang pesat beberapa tahun belakangan. Salah satunya dalam topik identifikasi sistem dan pemodelan sistem, yang merupakan hal penting dalam menentukan model terbang pesawat udara tanpa awak.Model terbang sendiri sangat penting dalam studi gerak terbang pesawat. Dalam penelitian ini, identifikasi sistem dilakukan berdasarkan data eksperimen dari pesawat udara tanpa awak jenis Bixler dan menggunakan struktur model Autoregressive with exogenous Input (ARX). Penelitian ini terdiri dari 2 tahap, pengambilan data terbang dan identifikasi model terban.Melalui 2 tahap tersebut, model terbang pesawat udara tanpa awak direpresentasikan dalam 2 mode, mode longitudinal dan mode lateral. Mode longitudinal diperoleh dengan struktur model $A R X$ dengan nilai orde $A=1$ dan $B=1$. Mode lateral diperoleh dengan struktur model $A R X$ dengan nilai orde $A=2$ dan $B=2$.
\end{abstract}

Kata Kunci: system identification, system modelling, $A R X$

\section{PENDAHULUAN}

Perkembangan teknologi UAV (unmanned aerial vehicle) atau pesawat tanpa awak semakin berkembang luas dengan semakin banyaknya penggunaan UAV di dunia. Teknologi UAV sendiri pada dasarnya sama dengan pesawat berawak. Pada UAV terdapat sistem aerodinamika, kontrol atau kendali, propulsi, komunikasi, dan lain-lain. Namun yang membedakannya dengan pesawat berawak, sistem kontrol dan komunikasi memegang peranan besar dalam operasional sebuah UAV. Hal ini dikarenakan UAV dikendalikan dari jauh jauh, sehingga kendali diberikan melalui komunikasi tanpa kabel (wireless). Karena posisi yang penting tersebut, maka perlunya dilakukan penelitian-penelitian mengenai sistem kontrol dan komunikasi UAV ke depannya.

Sebagai sebuah sistem yang memiliki peran penting dalam sebuah UAV, sistem kontrol dapat dibagi menjadi beberapa bidang, diantaranya sistem kendali mandiri (autopilot), logika terbang, model terbang, logika navigasi, dan lainnya. Model terbang diperlukan agar dalam UAV memiliki kontrol yang presisi, karena model terbang dapat merepresentasikan gerak terbang UAV.

Pada pemodelan terbang UAV, dikenal teknik identifikasi sistem. Identifikasi sistem adalah teknik pemodelan dengan menggunakan datadata input dan output dari sistem, yang kemudian dengan struktur model tertentu akan menghasilkan model yang akan menjadi representasi dari sebuah sistem. Untuk struktur model yang dipakai pada penelitian ini, digunakan struktur ARX, yang merupakan struktur yang paling sederhana dalam identifikasi sistem. Data yang digunakan untuk identifikasi sistem dengan struktur ARX ini menggunakan data terbang pesawat udara tanpa awak sayap tetap. Sehingga perlu dilakukan pengambilan data terbang.

\section{METODE PENELITIAN}

\subsection{Identifikasi sistem}

Identifikasi sistem adalah metedologi untuk membangun model matematika dari suatu sistem dinamis berdasarkan perhitungan dari sinyal input dan output sistem. Secara konsep, identifikasi sistem merupakan pemodelan sistem dinamis dari data yang dihasilkan dalam eksperimen [1].

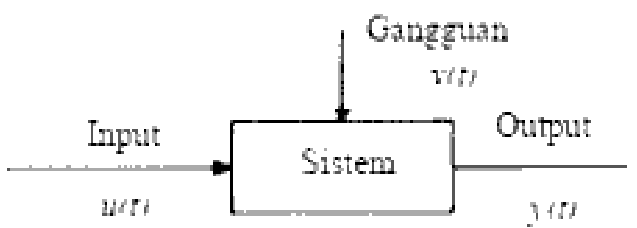

Gambar 1. Sistem dinamis dengan input $u(t)$, output $y(t)$ dan gangguan disturbancev $(\mathrm{t})$, dengan $\mathrm{t}$ menunjukkan waktu [2]

Identifikasi sistem melibatkan tiga unsur dasar berikut:

1. Data input dan output.

2. Struktur model.

3. Kriteria untuk memilih model tertentu dalam mengatur data berdasarkan informasi dalam data.

Langkah-langkah identifikasi sistem dapat dijabarkan sebagai berikut:

\footnotetext{
${ }^{1}$ Abdul Majid adalah Mahasiswa Prodi Elektronika dan Instrumentasi Jurusan Ilmu Komputer dan Elektronika FMIPA UGM, Anggota Divisi Kajian Lembaga Kajian Pertahanan untuk Kedaulatan NKRI "KERIS". Penulis dapat dihubungi melalui email

dialamat: dokmajid@yahoo.co.id

${ }^{2}$ Drs. Tri Kuntoro Priyambodo M.Sc., adalah Dosen Jurusan IImu Komputer dan Elektronika FMIPA UGM. Penulis dapat dihubungi melalui email dialamat: mastri.ugm@gmail.com
} 


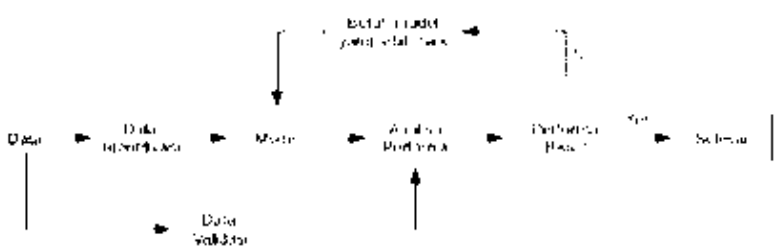

Gambar 2. Langkah-langkah identifikasi sistem [3]

\subsection{Struktur Model ARX}

AR-Auto Regressive yaitu output yang dihasilkan saat ini (current) berhubungan dengan nilai output sebelumnya (previous). X-eXogenous Inputs yaitu sistem tidak hanya bergantung pada input saat ini (current) tetapi juga berdasarkan rekam jejak (history) input. ARX merupakan model untuk sistem identifikasi yang paling sederhana. Model ARX memasukkan gangguan ke dalam sistem yang diidentifikasi itu sendiri. Bentuk umum model ARX:

$A(q) y(t)=B(q) u(t-n k)+e(t)$

(1)

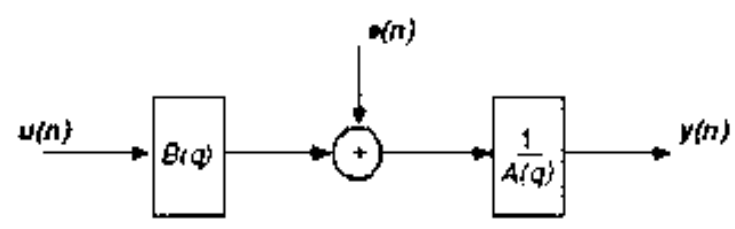

Gambar 3. Struktur Model ARX [4]

\subsection{Pesawat Udara Tanpa Awak}

Pada umumnya pesawat udara tanpa awak sama dengan pesawat udara berawak, terdapat beberapa parameter gaya, kecepatan, dan orientasi yang bekerja sesuai dengan yang ditunjukkan gambar dibawah ini.

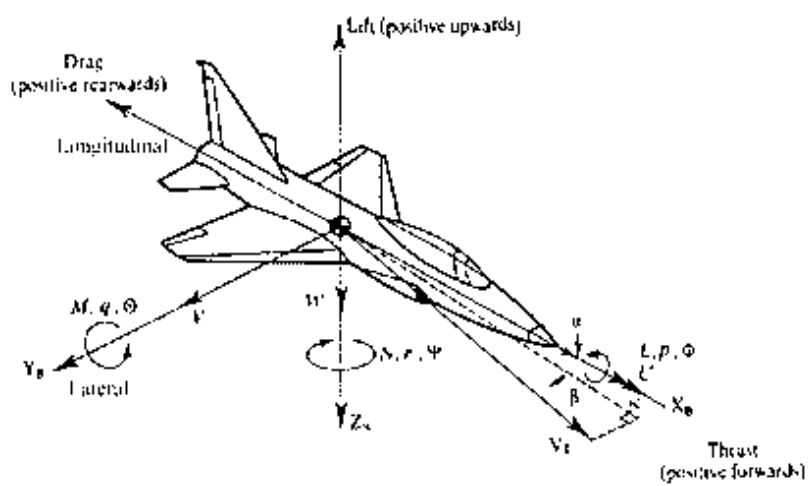

Gambar 4. Definisi gaya, kecepatan, momen, dan orientasi pesawat [5]
Dengan:

$u, v, w \quad K e c e p a t a n t r a n s \mid a s i$ padasumbu $x$, sumbu $y$, dan sumbu $z$

$L, M$, Momen aerodinamika sumbu $x, y$, dan $z$

$\phi, \theta, \psi$ Sudut roll, pitch, dan yaw

$p, q, r$ Kecepatan sudut roll, pitch, dan yaw

$\alpha \quad$ Sudut serang pesawat angle-of-attack

(AOA)

$\beta \quad$ Sudut sideslip

$\delta_{a} \quad$ Defleksi elevator

$\delta_{a} \quad$ Defleksi aiteron

Gerak terbang pesawat dapat dibagi 2:

1. Gerak terbang mode longitudinal, yaitu gerak translasi pesawat pada sumbu $x$ dan $z$, serta gerak rotasi pesawat pada sumbu y. Gerak ini dibutuhkan untuk gerak naik-turun pesawat. Untuk kontrol naik-turun pesawat, digunakan elevator pesawat.

2. Gerak terbang mode lateral, yaitu gerak translasi pesawat pada sumbu y, serta gerak rotasi pesawat pada sumbu x dan z. Gerak ini dibutuhkan untuk gerakan membelok pesawat (belok kanan-kiri). Untuk kontrol belok kanan-kiri pesawat, digunakan aileron pesawat.

\subsection{Rancangan Keseluruhan Penelitian}

Secara umum, penelitian ini dibagi menjadi 2 bagian, yaitu pengambilan data terbang dan identifikasi sistem. Pengambilan data terbang dilakukan sesuai dengan dengan input yang diberikan oleh operator yang dikirimkan melalui radio controller. Identifikasi sistem dilakukan menggunakan software Matlab.

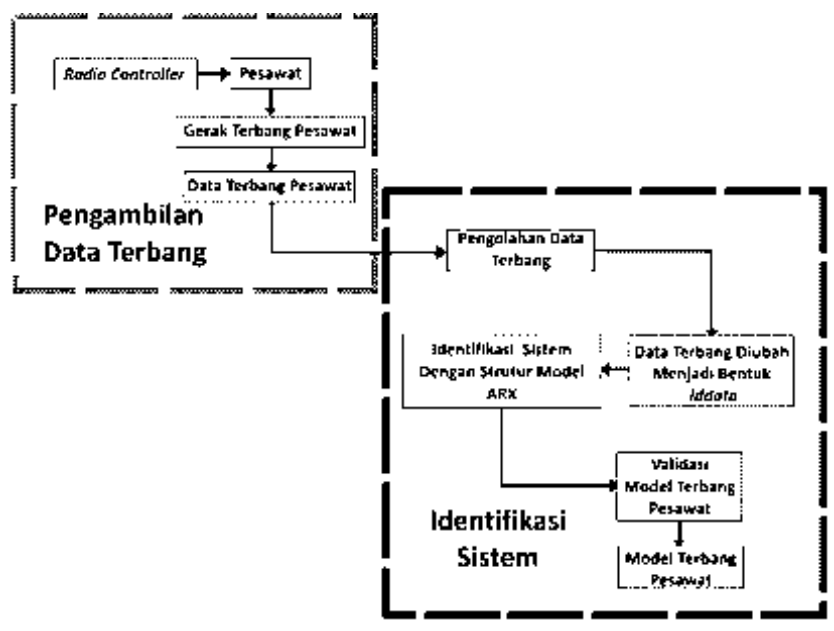

Gambar 5. Rancangan Keseluruhan Penelitian 


\subsection{Implementasi Perangkat Keras}

Implementasi perangkat keras dari penelitian ini adalah sebagai berikut:
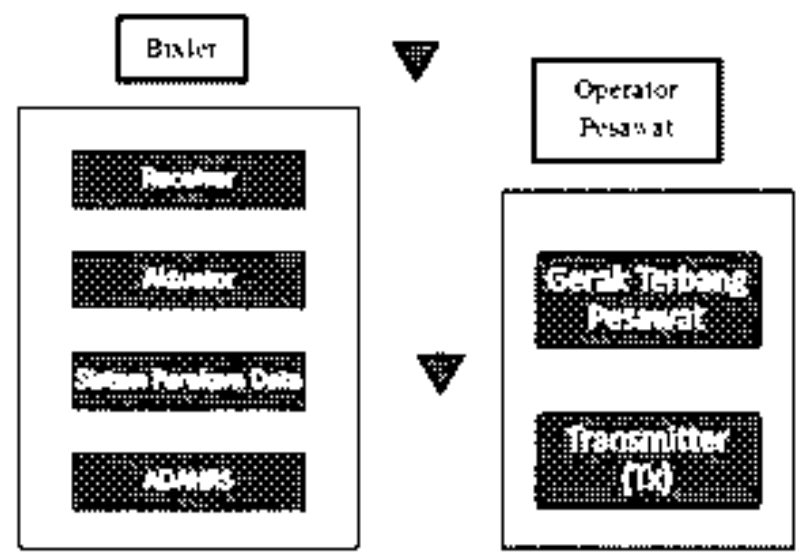

Gambar 6. Implementasi Perangkat keras

\subsubsection{Implementasi Pesawat}

Pesawat yang digunakan adalah pesawat Radio Controller (RC) Bixler. Pesawat Bixler merupakan pesawat yang banyak dipakai dalam dunia aeromodeling. Pesawat ini dilengkapi 4 sistem kendali (aileron, rudder, elevator, dan throttle). Pesawat ini berjenis glider. Pesawat berjenis glider dikenal sebagai pesawat yang memiliki performa terbang yang baik, stabil, dan mudah dikendalikan. Pesawat Bixler mempunyai ruang yang cukup besar dalam fuselage/badan pesawat. Karena kestabilan, mudah dikendalikan, dan memiliki ruang besar inilah pesawat Bixler banyak digunakan misi-misi tertentu seperti untuk pemotretan udara. Berikut ini data teknis pesawat bixler [6].
- Material : EPO Foam
- Lebar sayap: $1400 \mathrm{~mm}$
- Panjang : $925 \mathrm{~mm}$
- Luas sayap : 26d m2
- Berat $\quad: 650 \mathrm{~g}$
- Motor :620-1900kv Brushless

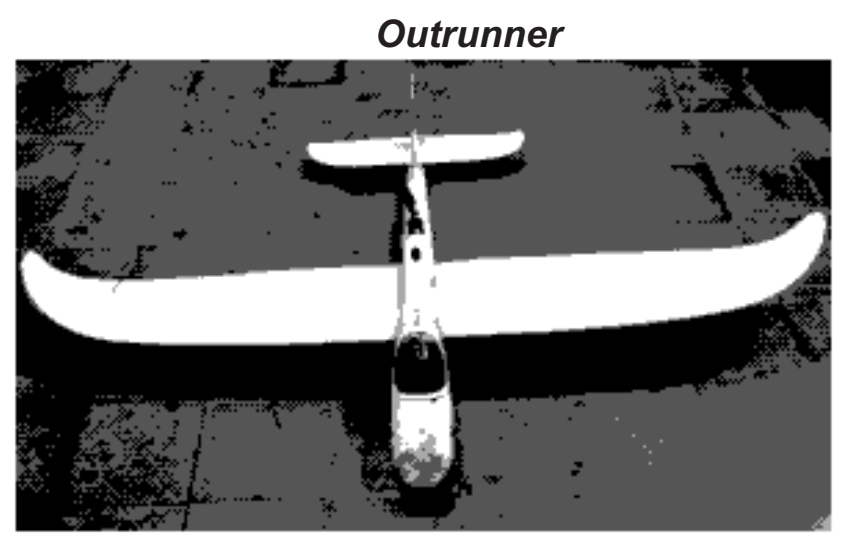

Gambar 7. Implementasi Pesawat Bixler

\subsubsection{Implementasi Transmitter dan Receiver}

Transmitter dan receiver yang digunakan adalah jenis Futaba FASST 7C yang memiliki 7 Channel. Transmitter dan receiver ini sudah cukup untuk penelitian ini, sebab pesawat Bixler yang digunakan hanya membutuhkan 4 Channel yaitu Channel 1-4. Futaba FASST 7C memiliki frekuensi $2.4 \mathrm{GHz}$ dan memiliki jarak jangkau sekitar 400-500 meter dengan kualitas sinyal yang dihasilkan salah satu yang terbaik dikelasnya.

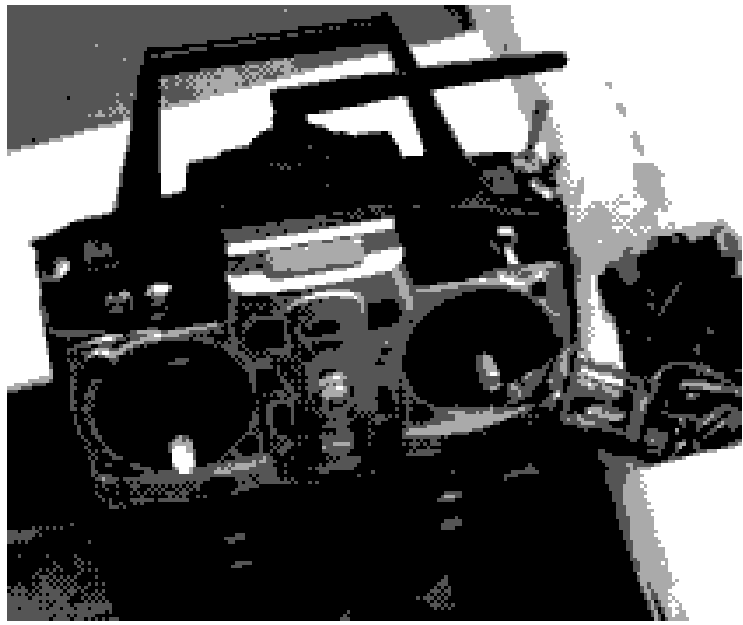

Gambar 8. Implementasi Transmitter dan Receiver

\subsubsection{Implementasi Aktuator}

Aktuator yang digunakan adalah miniservo dan brushless-motor. 4 buah miniservo digunakan untuk mengontrol aileron, elevator, dan rudder. Aileron membutuhkan 2 mini-servo karena terdapat 2 aileron, aileron sayap kiri dan aileron sayap kanan. Sedangkan untuk mengontrol brushlessmotor, dihubungkan dengan ESC (Electronic Speed Controller) terlebih dahulu sebelum dihubungkan dengan brushless-motor. Semua aktuator dihubungkan dengan RC receiver. Berikut ini pengaturan hubungan $\mathrm{RC}$ receiver dengan aktuator:

1. Channel 1 dihubungkan dengan 2 miniservoaileron.

2. Channel 2 dihubungkan dengan miniservo elevator.

3. Channel 3 dihubungkan dengan ESC.

4. Channel 4 dihubungkan dengan miniservo rudder. 
Selain dihubungkan dengan aktuator, port channel 1-4 receiver dihubungkan pula dengan Arduino Due (basis ADAHRS) melalui modul aktuator. Fungsinya yaitu sebagai parallel dari $\mathrm{RC}$ receiver agar input yang dikirimkan oleh transmitter dapat dibaca dan kemudian direkam oleh modul perekam data. Berikut ini implementasi dari modul aktuator.

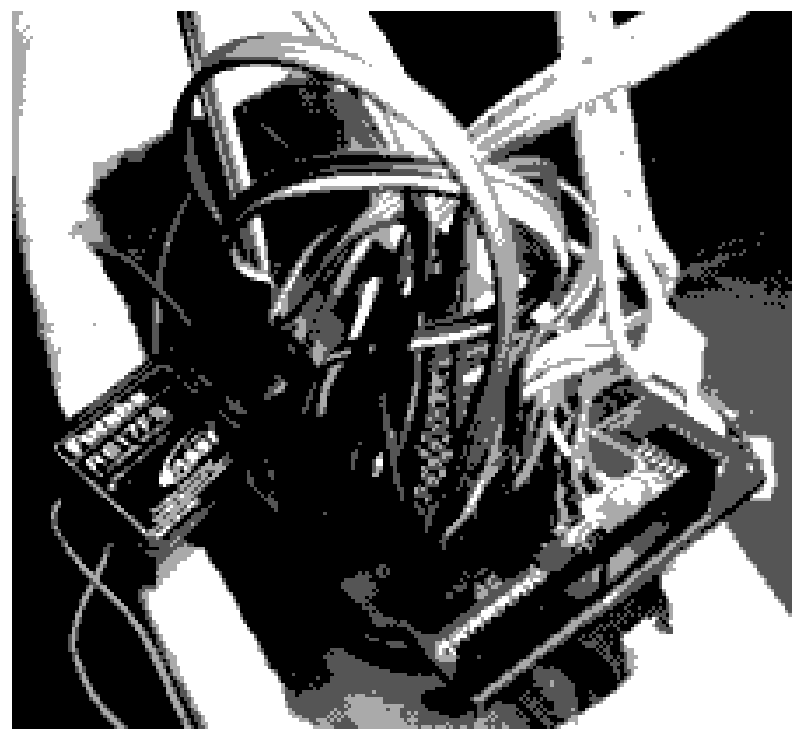

Gambar 9. Skema modul aktuator dengan Arduino Due

\subsubsection{Implementasi ADAHRS dan Perekam Data}

ADAHRS adalah sebuah sistem yang mengukur data-data sikap pesawat. ADAHRS terdiri dari beberapa sensor seperti IMU (inertial Measurement Unit) yang terdiri dari accelerometer, gyroscope, dan magnetometer, kemudian barometer, pressure sensor, dan GPS (Global Positioning System) receiver. Accelerometer dan gyroscope berfungsi memantau sikap pesawat (sudut roll, pitch, dan yaw), magnetomer berfungsi memantau arah terbang pesawat, barometer berfungsi untuk memantau ketinggian terbang pesawat terhadap permukaan laut, pressure sensor berfungsi untuk memantau kecepatan pesawat (dengan dihubungkan dengan probe), serta GPS receiver berfungsi untuk memantau posisi pesawat serta kecepatan dan ketinggian pesawat (dibandingkan dengan data dari barometer dan pressure sensor). Data dari sensor-sensor tersebut kemudian diolah di mikrokontoler /mikroprosessor kemudian disimpan dalam memori yang ada dalam sistem ADAHRS atau mengirimkannya ke sistem lain pada pesawat yang membutuhkan seperti sistem Auto Pilot atau mengirimkannya ke darat melalui perangkat telemetry.

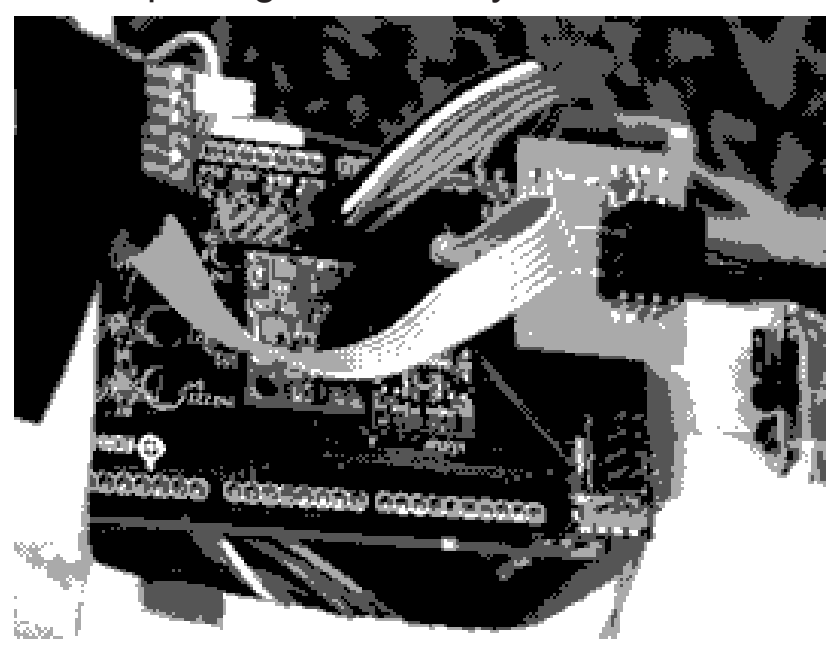

Gambar 10. Implementasi ADAHRS

Spesifikasi dari ADAHRS yang digunakan[7]:

Kontroler : Arduino Due

Sensor-sensor :

Sensor IMU : MPU6050 dan HMC5883S

Sensor Ketinggian :Ms611

Sensor Kecepatan Udara : MPXV5004D GPS : SKM53

\begin{tabular}{|c|c|}
\hline Parameter & Spesifikasi \\
\hline Yaw & $\begin{array}{l}\text { - Offset } 0,2^{\circ} \\
\text { - Standar Deviasi Statis } \\
0,07^{\circ} \\
\text { - Ralat rata-rata } 0,25^{\circ}\end{array}$ \\
\hline Pitch & $\begin{array}{l}\text { - Offset } 0,14^{\circ} \\
\text { - Standar Deviasi Statis } \\
0,04^{\circ} \\
\text { - Ralat rata-rata } 0,24^{\circ}\end{array}$ \\
\hline Roll & $\begin{array}{l}\text { - Offset } 0,6^{\circ} \\
\text { - Standar Deviasi Statis } \\
0.18^{\circ} \\
\text { - Ralat rata-rata } 0,64^{\circ}\end{array}$ \\
\hline $\begin{array}{l}\text { Ketinggian } \\
\text { barometrik }\end{array}$ & $\begin{array}{l}\text { - Ralat rata-rata 0,63 m } \\
\text { - Standar Deviasi 0,17 m }\end{array}$ \\
\hline $\begin{array}{c}\text { Kecepatan } \\
\text { udara }\end{array}$ & $\begin{array}{l}\text { - Ralat rata-rata } 13,85 \\
\text { km/jam } \\
\text { - Standar deviasi 2,31 } \\
\text { km/jam }\end{array}$ \\
\hline GPS & $\begin{array}{l}\text { - Ralat rata-rata koordinat } \\
6,68 \mathrm{~m} \\
\text { - Ralat rata-rata } \\
\text { ketinggian } 12,58 \mathrm{~m}\end{array}$ \\
\hline
\end{tabular}

Tabel 1. Spesifikasi ADAHRS [7] 
Untuk merekam data yang dibaca oleh ADAHRS dan modul aktuator, diperlukan sebuah sistem perekam data. Media penyimpanan yang digunakan berupa Micro SD. Digunakan modul Micro SD yang diproduksi oleh Sparkfun Electronics sebagaimana Gambar 11 berikut ini.

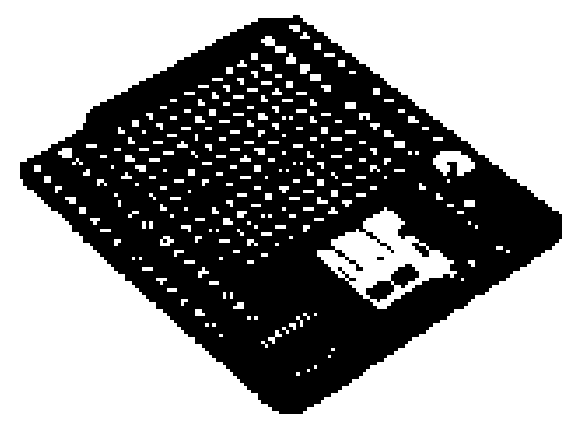

Gambar 11. Modul micro SD [8]

Untuk pemrosesannya digunakan Arduino Due yang ada pada ADAHRS. Hal ini dilakukan karena masih tersedianya port kosong pada Arduino Due yang dapat digunakan untuk sistem perekam data. Gambar 9 dibawah ini menggambarkan skema wiring modul micro SD dengan Arduino Due.
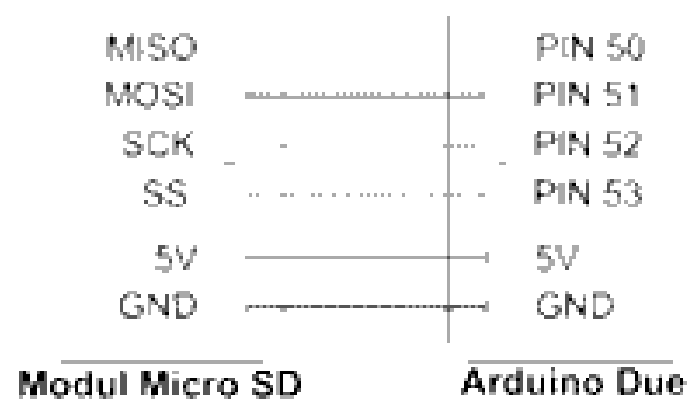

Gambar 12. Skema wiring modul micro SD card dan Arduino Due

\subsection{Implementasi Pengambilan Data Terbang}

Pengambilan data terbang mencakup 2 hal, data input dan output pesawat. Data input meliputi data input yang diberikan kepada aktuator melalui radio controller, sedangkan data output meliputi data sikap, posisi, dan kecepatan pesawat. Data terbang yang dihasilkan berguna untuk tahap selanjutnya, yaitu identifikasi model terbang pesawat.

Pengambilan data terbang perlu direncanakan dengan baik, agar sesuai dengan yang diharapkan. Untuk penelitian ini, input pada pesawat berupa doublet input. Doublet input adalah variasi input dengan diberikan sinyal PWM tinggi selama waktu $t$ dan kemudian langsung diberikan sinyal PWM rendah selama waktu t pula. Doublet input banyak digunakan oleh peneliti-peneliti di dunia dalam melakukan pemodelan dan identifikasi model terbang pesawat, termasuk perusahaan pembuat pesawat Boeing ketika melakukan identifikasi sistem pesawat tempur F-15 Eagle [9]. Gambar 13 berikut adalah bentuk dari sinyal doublet input.

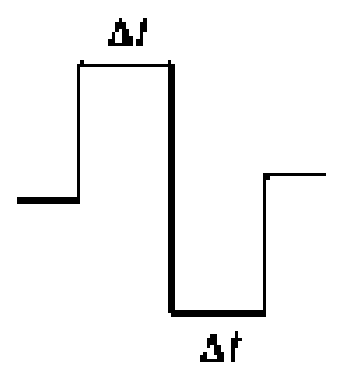

Gambar 13. Bentuk sinyal doublet input[10]

Pada penelitian ini pemodelan akan dibagi 2, mode longitudinal dan mode lateral. Pada mode longitudinal, doublet input diberikan pada channel 2 atau elevator, kemudian pada mode lateral, doublet input diberikan pada channel 1 yaitu aileron. Sebelum diberikan doublet input, peswat dikondisikan dalam keadaan trim dan level, yaitu pesawat dianggap dalam keadaan terbang lurus dan sayap kanan-kiri pesawat dalam keadaan sama secara horizontal. Diagram prosedur pengambilan data terbang dapat dilihat pada Gambar 11 berikut.

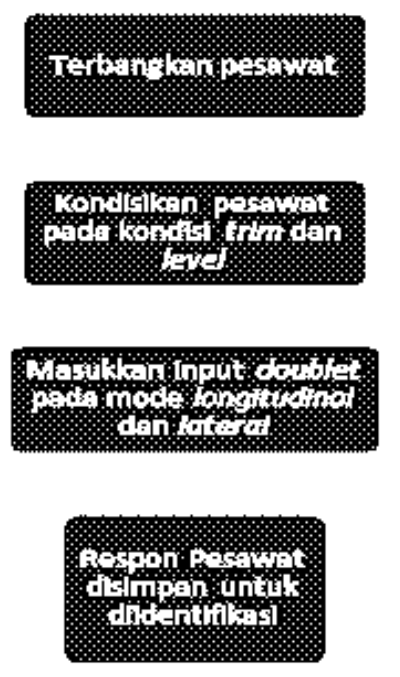

Gambar 14. Diagram prosedur pengambilan data terbang 


\subsection{Implementasi Identifikasi Sistem}

Identifikasi model terbang pesawat udara tanpa awak sayap tetap pada penelitian ini menggunakan struktur model ARX. Struktur model ini sudah merupakan struktur model untuk identifikasi sistem yang paling sederhana. Metode ini cukup banyak digunakan pada pemodelan pesawat udara tanpa awak, terutama yang berukuran min dan mikro. Padasoftware Matlab yanc digunakan, sudah tersedia tools untuk identifikasi sistem yang dinamakan SITB (System Identification Toolbox).

Identifikasi sistem yang dilakukan pada penelitian ini dapat dibagi menjadi 2 yaitu mode longitudinal dan mode lateral. Data terbang yang diperoleh, akan diolah terlebih dahulu, yaitu dilakukan filtering dar penyesuaian parameter yang digunakan. Kemudian data terbang yang telah diolah, ditentukan data yang akan dipakai untuk identifikasi. Untuk identifikasi dibutuhkar input, output, dan sampling rat $\epsilon$ instrumentasi yang digunakan. Input untuk identifikasi sistem penelitian ini adalah defleksi elevator untuk mode longitudinal dar defleksi aileron untuk mode lateral. Sedangkan output nya adalah perubahar kecepatan sudut pada sumbu y $(\Delta q)$ ntuk mod $\epsilon$ longitudinal dan perubahan kecepatan sudul sumbu $x(\Delta p)$ pada mode lateral. Sedangkan sampling rate yang digunakan sama untuk keduan mode, yaitu $10 \mathrm{~Hz}$.

Setelah model dihasilkan, dilakukan validasi dengan mensimulasikan antara model dengan data terbang asli. Input model adalah input yang sama dengan data terbang asli. Validasi ini akan menghasilkan tingkat kecocokan grafik yang dihasilkan model dengan data terbang asli. Metode yang digunakan untuk menghitung kecocokan ini adalah menggunakan metode best fit, yang memiliki rumus:

$$
\text { Best Fit }=\left(1-\frac{|y-\hat{y}|}{|y-\bar{y}|}\right) \times 100 \%
$$

Nilai y adalah nilai output data terbang, nilai $\hat{y}$ adalah nilai output yang dihasilkan model sistem yang diperoleh, sedangkan nilai $\bar{y}$ adalah nilai rata-rata dari y. (Mathwork, 2012). Selain simulasi output model dengan data terbang asli, akan dilakukan pula prediksi model dengan predictiontools yang ada di Matlab, tujuannya adalah mencoba menganalisa apakah model yang dihasilkan apakah kedepannya masih dapat dikembangkan lagi atau tidak. Secara umum Langkah-langkah identifikasi sistem dapat dirangkum seperti pada Gambar dibawah ini.

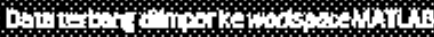

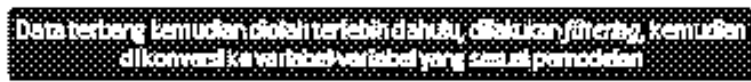

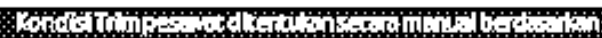

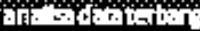

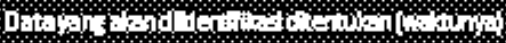
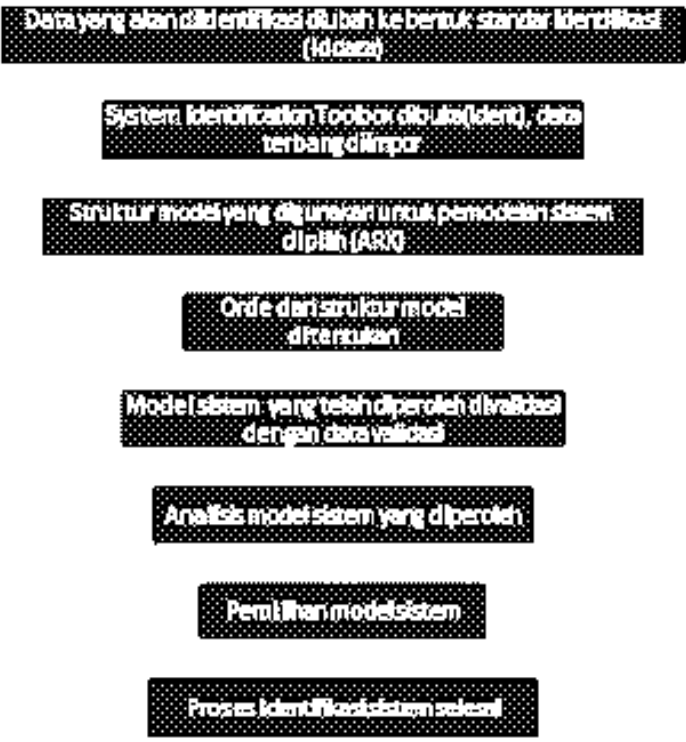

Gambar 15. Diagram langkah-langkah identifikasi sistem

\section{HASIL DAN PEMBAHASAN}

Bagian ini akan menerangkan hasil dan pembahasan dari identifikasi sistem yang telah dilakukan pada penelitian ini.

\subsection{Hasil Pengambilan Data Terbang}

Dari pengambilan data terbang sebanyak 2 sortie, didapat data sebesar $761 \mathrm{~Kb}$ yang berisi 11.607 data. Berikut adalah data-data yang dihasilkan pada saat pengambilan data terbang yaitu data sikap pesawat pada Gambar 16, data input pesawat pada Gambar 17, dan data posisi pesawat pada Gambar 18. 


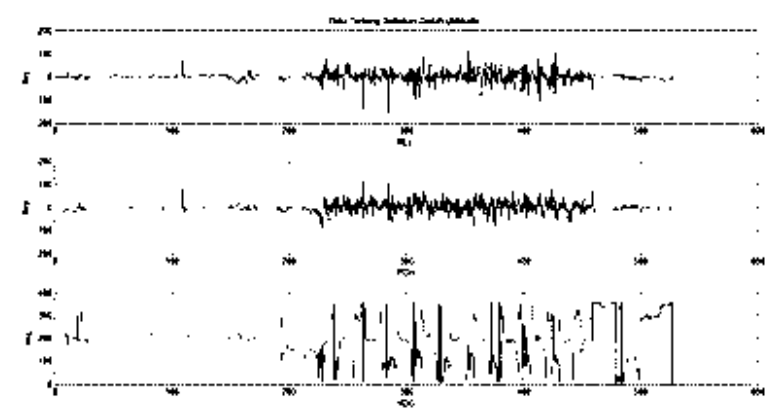

Gambar 16. Grafik data sikap pesawat (sudut roll, pitch, dan yaw)

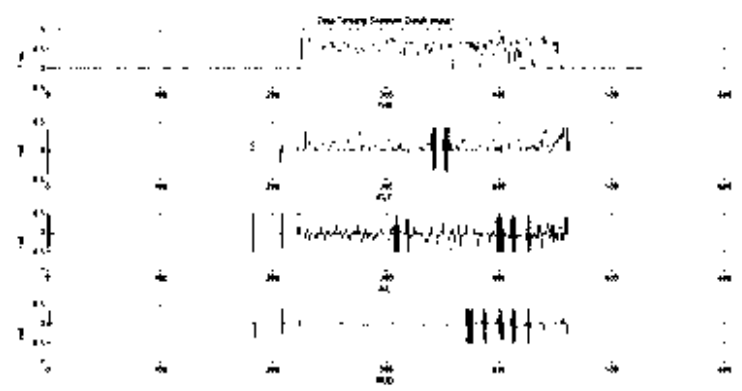

Gambar 17. Grafik data input pesawat (throttle, elevator, aileron, dan rudder)

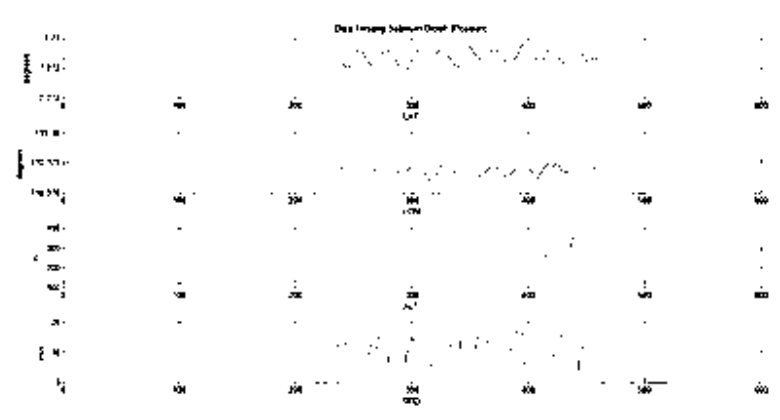

Gambar 18. Grafik data posisi pesawat (latitude, longitude, altitude, dan speed)

\subsection{Hasil identifikasi Sistem}

Padaproses identifikasi sistem, setelah data diolah dan disesuaikan dengan parameter-parameter yang digunakan, dilakukan penentuan kondisi trim pesawat. Kondisi trim pesawat adalah saat

$u \neq 0, w=0, q=0, \operatorname{dan} \theta \neq 0$. Penentuan ini dilakukan secara manual. Didapatkan kondisi trim pesawat yang digunakan, yaitu pesawat RC Bixler sebagai berikut:

\begin{tabular}{|cc|}
\hline Parameter & Nilai \\
\hline Sudut pitch $(\theta)$ & 0.25 \\
\hline Sudut roll $(\phi)$ & -0.28 \\
\hline $\begin{array}{c}\text { Sudut defleksi } \\
\text { elevator }\end{array}$ & 0.002 \\
\hline $\begin{array}{c}\text { Sudut defleksi } \\
\text { aileron }\end{array}$ & -0.03 \\
\hline
\end{tabular}

Tabel 2. Kondisi trim pesawat

Data yang akan diidentifikasi dapat dilihat pada Gambar 19 untuk mode longitudinal, dan Gambar 20 untuk mode lateral.

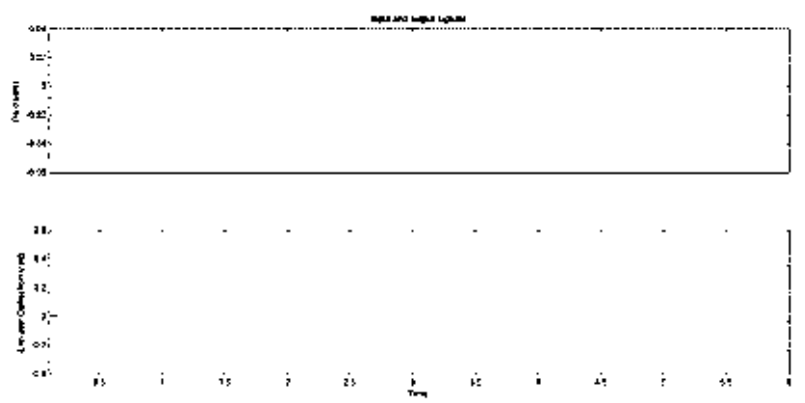

Gambar 19. Data identifikasi untuk mode longitudinal, input defleksi elevator dalamrad (bawah) dan output $\Delta q$ dalam rad/s (atas)

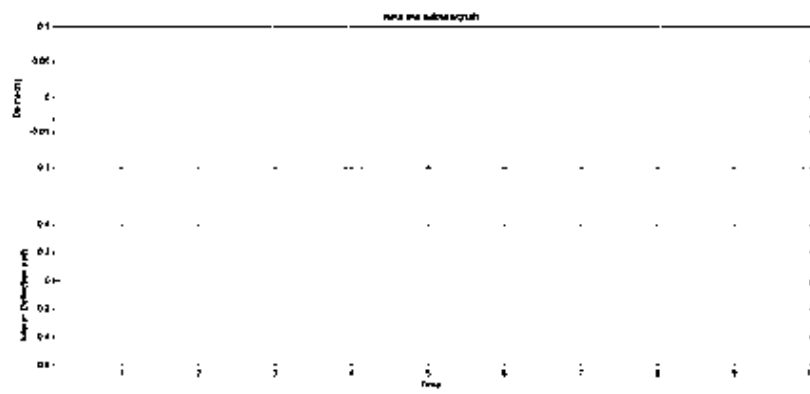

Gambar 20. Data identifikasi untuk mode lateral, input defleksi aileron dalamrad(bawah) dan $\Delta q$ dalam rad/s (atas)

Dari data inputdan output yang dipilih untuk identifikasi tersebut, kemudian dilakukan identifikasi sistem. Pada identifikasi sistem penelitian ini dilakukan pemilihan orde model struktur ARX pada kedua mode. Orde yang digunakan sesuai tabel 3 berikut ini.

\section{Mode}

\section{Orde [Na Nb Nk]}

\begin{tabular}{|cc|}
\hline Longitudinal & {$\left[\begin{array}{lll}1 & 1 & 1\end{array}\right]$} \\
\hline Lateral & {$\left[\begin{array}{lll}2 & 2 & 1\end{array}\right]$} \\
\hline
\end{tabular}

Tabel 2. Orde yang digunakan 
Dasar dari pemilihan orde tersebut adalah dengan melihat tingkat keakuratan terbaik. Semakin tinggi orde yang digunakan, maka tingkat keakuratan akan semakin baik. Namun jika perubahan tingkat keakuratan yang terjadi tidak terlalu signifikan, maka digunakan orde sebelumnya.

Kemudian model yang hasilnya divalidasi dengan metode simulasi dan prediksi yang ditunjukkan pada Gambar 21 dan Gambar 22 untuk mode longitudinal serta Gambar 23 dan Gambar 24 untuk mode lateral.

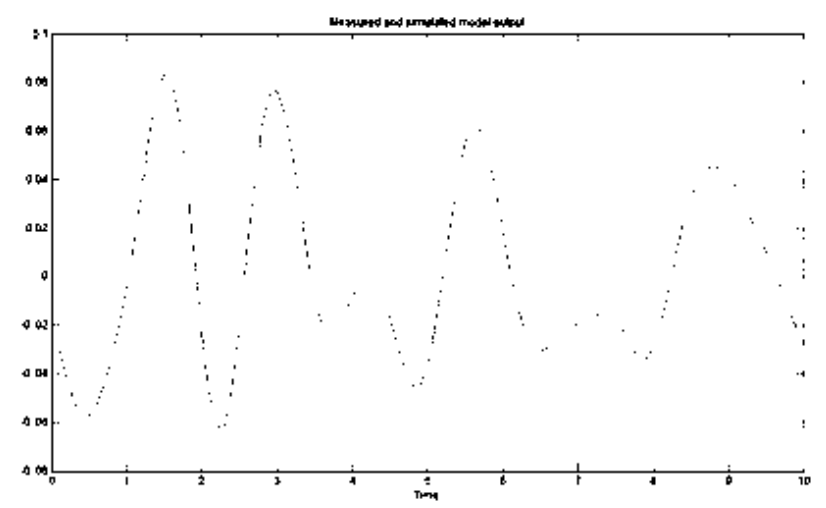

Gambar 21. Grafik perbandingan data terbang vs simulasi mode longitudinal

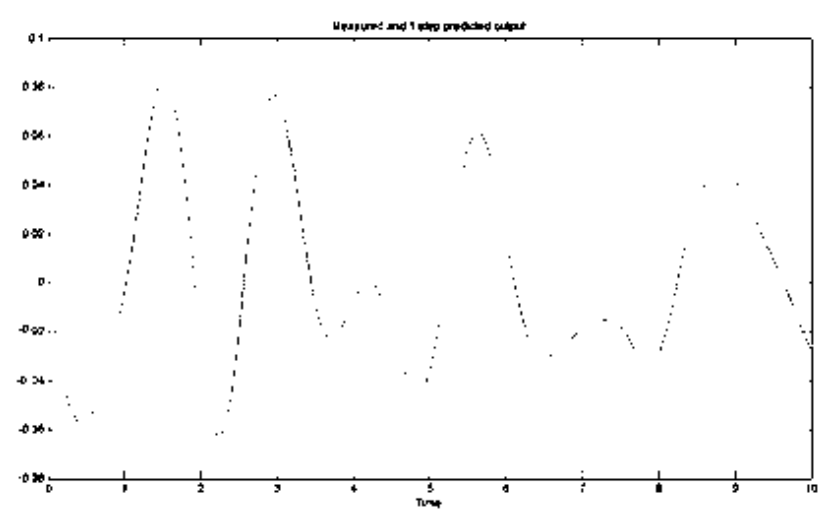

Gambar 22. Grafik perbandingan data terbang vs prediksi mode longitudinal

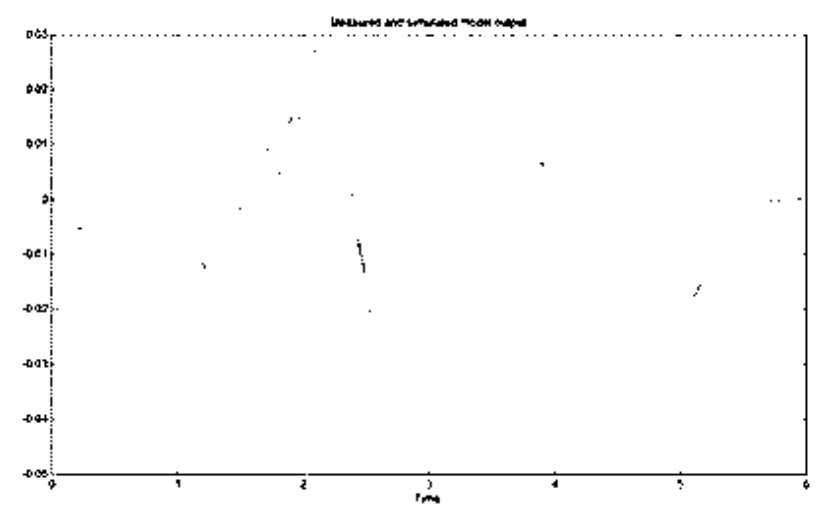

Gambar 23. Grafik perbandingan data terbang vs simulasi mode lateral

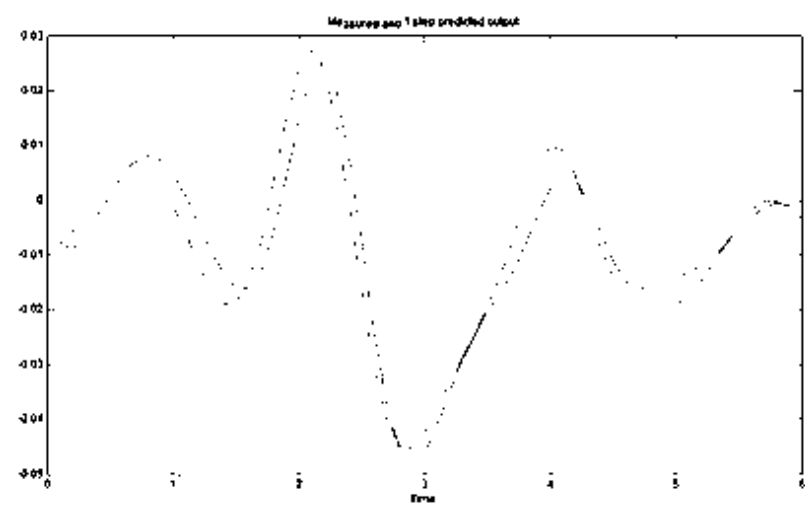

Gambar 24. Grafik perbandingan data terbang vs prediksi mode lateral

Pada mode longitudinal, didapatkan tingkat keakuratan $30.48 \%$ pada simulasi dan $71.43 \%$ pada prediksi. Pada mode lateral didapatkan tingkat keakuratan $23.92 \%$ pada simulasi dan $94.49 \%$ pada prediksi. Perbedaan metode simulasi dan prediksi terletak bagaimana mengolah input yang diberikan. Metode simulasi menghasilkan output langsung dengan memasukkan input ke dalam model (persamaan model) yang dihasilkan. Sedangkan metode prediksi selain menggunakan hasil dari persamaan model, metode ini melihat pula data sebelumnya (history). Dengan begitu tingkat keakuratannya akan semakin baik. Tingkat keakuratan pada identifikasi sistem pesawat udara tanpa awak sayap tetap ini sangat dipengaruhi oleh beberapa hal terutama faktor alam, seperti angin, termal, cuaca, dan lainnya. Pada pengambilan data terbang dilakukan pada pagi hari, dengan harapan agar gangguan angin dapat diminimalisir, tetapi gangguan angin masih menjadi hambatan dalam identifikasi sistem ini, dapat dilihat pada saat input diberikan, respon pesawat tidak cukup cepat. Hal tersebut akan mengakibatkan tingkat keakuratan menurun. Namun hal itu masih dapat ditolerir, dapat dilihat dari tingkat keakuratan pada metode prediksi yang cukup baik. Model dapat digunakan meskipun pada simulasi menghasilkan nilai kurang baik, selama pada prediksi menghasilkan tingkat keakuratan yang cukup baik [8].

\subsection{Model Yang Dihasilkan}

Model yang dihasikan pada mode longitudinaldengan strutur ARX adalah sesuai Persamaan 4. 


$$
\begin{gathered}
A(q) y(t)=B(q) u(t-n k)+e(t) \\
A(z)=1-1.151 z^{n-1} \\
B(z)=0.0206 z^{n-1}
\end{gathered}
$$

Dengan: $N a=1, N b=1$, dan $N k=1$

Model yang dihasikan pada mode fateral adalah sesuai Persamaan 6.

$$
\begin{aligned}
& A(q) y(t)=B(q) u(t-n k)+e(t) \\
& A(z)=1-1.8 z^{n-1}+0.8901 z^{n-2} \\
& B(z)=-0.02622 z^{n-1}+0.0277 z^{n-2}
\end{aligned}
$$

Dengan: $\mathrm{Na}=2, \mathrm{Nb}=2$, dan $\mathrm{Nk}=1$

\section{PENUTUP}

\subsection{Kesimpulan}

Berdasarkan penelitian yang telah dilakukan, dapat diambil kesimpulan sebagai berikut:

1. Telah berhasil dilakukan model yang dapat merepresentasikan pesawat tanpa awak sayap tetap jenis Bixler dengan struktur model ARX.

2. Dihasilkan persamaan model:

- Model mode iongitudinal

$$
\begin{gathered}
A(q) y(t)=B(q) u(t-n k)+e(t) \\
A(z)=1-1.151 z^{n-1} \\
B(z)=0.0206 z^{n-1}
\end{gathered}
$$

Dengan: $N a=1, N b=1$, dan $N k=1$

- Model mode lateral

$$
\begin{aligned}
& A(q) y(t)=B(q) u(t-n k)+e(t) \\
& A(z)=1-1.8 z^{n-1}+0.8901 z^{n-3} \\
& B(z)=-0.02622 z^{n-1}+0.0277 z^{n-3}
\end{aligned}
$$

Dengan: $\mathrm{Na}=2, \mathrm{Nb}=2$, dan $\mathrm{Nk}=1$

Nilan keakuratan masım Iy-m Iası Iy muver.

- Model mode longitudinal:

- $30.48 \%$ dengan metode simulasi

- $71.43 \%$ dengan metode prediksi

- Model mode lateral

- 23.92\%dengan metode simulasi

- $94.49 \%$ dengan metode prediksi

\subsection{Saran}

1. Perlunya instrumentasi yang memiliki samplingrate yang cepat dan akurasi yang tinggi untuk identifikasi sistem.

2. Diperlukan penelitian pada bentuk stuktur model yang lain agar dapat dibandingkan dengan penelitian ini.

\section{DAFTAR PUSTAKA}

Ljung L., 2011. System Identification Toolbox ${ }^{\mathrm{TM}}$ User's Guide. Natick: The MathWorks, Inc.

Söderström T. dan Stoica P. 2001. System Identification. 2. London: Prentince Hall International.

Masiero, C. 2012. Matlab System Identi cation Toolbox Quickstart. [pdf] terdapat di <http://automatica.dei. unipd.it/tl_files/utenti2/masieroChiara/Mi scellaneā/Matlab_Sysld_Tutorial.pdf> [diakses pada 23 November 2013].

National Instruments. 2011. Selecting a Model Structure in the System Identification Process. [online] terdapat di : <http://www. ni.com/whitepaper/4028/en> [diakses pada 20 November 2013].

McLean, D. 1990. Automatic Flight Control System. Prentice Hall Inc.

Hobbyking. 2011. Bixler v1.1 EPO 1400mm [online] terdapat di : <http://hobbyking. com/hobbyking/store/_16543_Bixler v1_1_EPO_1400mm_RTF_Mode_1_Th rottle Right Radio . $\overline{\text { html }}>$ [diakses pada 20 Novembēr 2013].

Pratama, F. 2013. Sistem Referensi Air Data, Attitude, And Heading Reference System Pada Pesawat Terbang Tanpa Awak. Skripsi.Yogyakarta: Fakultas Matematika dan IImu Pengetahuan Alam. Universitas Gadjah Mada.

Sparkfun. 2013. Micro SD Shield. [online] terdapat di: <https://www.sparkfun.com/ products/9899> [diakses pada 1 November 2013].

Smith, M. S. dan Moes, T. R. 2003. Real-time Stability and Control Derivative Extraction from F15 Flight Data.AIAA Atmospheric Flight Mechanics Conference. AIAA-2003-5701. 


\title{
JUDUL SINGKAT MAKSIMAL 3 BARIS DITULIS DENGAN FONT ARIAL UKURAN 14
}

\author{
Penulis ${ }^{1}$, Penulis ${ }^{2}, \ldots \ldots . . .{ }^{\text {dst }}$
}

\begin{abstract}
Abstrak: Abstrak menjelaskan intisari dari penelitian yang dilakukan. Abstrak dapat menggunakan bahasa Indonesia untuk tulisan berbahasa Indonesia dan bahasa inggris untuk tulisan berbahasa Inggris. Jika menggunakan bahasa inggris penulisan abtrak ditulis italic. Banyaknya kata dalam abstrak antara 150 s.d 200 kata, jika terdapat istilah-istilah asing yang belum dibakukan maka ditulis italic. Font yang digunakan untuk menyusun abstrak adalah arial dengan ukuran 10 .
\end{abstract}

Kata Kunci: berisi maksimal 5 kata penting dalam penelitian yang ditulis italic dan dipisahkan dengan tanda, dengan ukuran font 11

\section{PENDAHULUAN}

Diisi dengan latar belakang dan tujuan dari penelitian yang dibuat. Untuk keseragaman maka gunakan istilah PENDAHULUAN untuk bagian pertama ini. Font yang digunakan untuk menyusun pendahuluan adalah arial dengan ukuran 11. Pastikan Anda tidak mengubah style yang ada pada template ini, meliputi jenis dan ukuran font, besar spasi, jarak indent, dan lain sebagainya. Banyaknya halaman untuk jurnal DEFENDONESIA adalah 6-10 halaman (mohon usahakan jumlah halaman GENAP) mulai dari judul hingga ke referensi.

\section{ISI PENELITIAN}

Bagian ini dapat dibagi dalam beberapa sub pokok pembahasan sesuai dengan kebutuhan tulisan. Tidak ada batasan yang baku mengenai jumlah pemerincian sub pokok bahasannya; tetapi setidaknya mengandung: metode, hasil, dan pembahasan, dan ditulis dengan font arial ukuran 11, sementara untuk sub bab dicetak tebal.

\begin{tabular}{|l|c|}
\hline Keterangan & Ukuran \\
\hline Judul & 14 \\
\hline Nama Penulis & 12 \\
\hline Abstrak & 8 \\
\hline $\begin{array}{l}\text { Kata Kunci, Tulisan Naskah, } \\
\text { Daftar Pustaka }\end{array}$ & 11 \\
\hline Identitas Tabel dan Gambar & 9 \\
\hline
\end{tabular}

\subsection{Sub Bab}

Sub bab ditulis dengan arial ukuran 11 dicetak tebal. Gambar dan tabel dapat dimasukkan dibagian ini dengan format seperti pada Gambar 1 dan Tabel 1. Keterangan tabel dan gambar diletakkan dibawah objek dengan ukuran font 9 seperti contoh berikut:

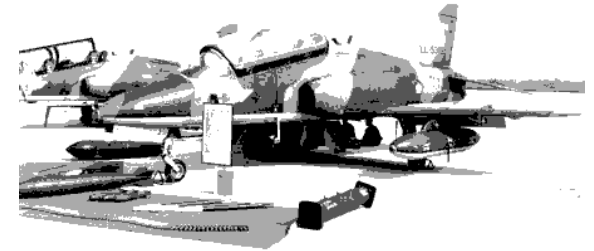

Gambar 1. Contoh Gambar

\begin{tabular}{|l|l|}
\hline Parame ter & Nilai \\
\hline Maksimal Perulangan & 100 \\
\hline Rasio Pe mbelajaran & 70 \\
\hline Minimal Eror & 80 \\
\hline
\end{tabular}

Tabel 1. Contoh Tabel

\section{PENUTUP}

Pada bagian ini, nomer bab penutup akan menyesuaikan seberapa jumlah bab pada bagian isi penelitian. Penutup berisikan kesimpulan penelitian, serta saran pengembangan untuk penelitian selanjutnya. Judul bab terakhir ini juga dibuat seragam yaitu PENUTUP.

\section{UCAPAN TERIMAKASIH}

Pada bagian ini (Opsional), Anda dipersilahkan memberikan ucapan terima kasih kepada pihak-pihak yang membantu penulisan /penelitian Anda.

\section{DAFTAR PUSTAKA}

Kepustakaan menganut sistematika penulisan referensi didasarkan pada Harvard system yang bersumber dari Anglia Ruskin University dengan ketentuan yang dapat dilihat di alamat http://libweb.anglia.ac.uk/ referencing/harvard.htm

${ }^{1}$ Informasi/deskripsi diri/CV penulis yang dilengkapi dengan tempat kerja/kampus jika masih kuliah/ beserta alamat email dan ditulis dengan font ukuran 8. 